\title{
Electrochromic Devices Based on Porous Tungsten Oxide Thin Films
}

\author{
Y. Djaoued, ${ }^{1}$ S. Balaji, ${ }^{1}$ and R. Brüning ${ }^{2}$ \\ ${ }^{1}$ Laboratoire de Recherche en Matériaux et Micro-Spectroscopies Raman et FTIR, Université de Moncton-Campus de Shippagan, \\ 218 Boulevard J.-D. Gauthier, Shippagan, NB, Canada E8S 1 P6 \\ ${ }^{2}$ Physics Department, Mount Allison University, 67 York Street, Sackville, NB, Canada E4L 1E6
}

Correspondence should be addressed to Y. Djaoued, yahia.djaoued@umoncton.ca

Received 29 May 2012; Accepted 22 June 2012

Academic Editor: Vo-Van Truong

Copyright () 2012 Y. Djaoued et al. This is an open access article distributed under the Creative Commons Attribution License, which permits unrestricted use, distribution, and reproduction in any medium, provided the original work is properly cited.

Recent developments in the synthesis of transition metal oxides in the form of porous thin films have opened up opportunities in the construction of electrochromic devices with enhanced properties. In this paper, synthesis, characterization and electrochromic applications of porous $\mathrm{WO}_{3}$ thin films with different nanocrystalline phases, such as hexagonal, monoclinic, and orthorhombic, are presented. Asymmetric electrochromic devices have been constructed based on these porous $\mathrm{WO}_{3}$ thin films. XRD measurements of the intercalation/deintercalation of $\mathrm{Li}^{+}$into/from the $\mathrm{WO}_{3}$ layer of the device as a function of applied coloration/bleaching voltages show systematic changes in the lattice parameters associated with structural phase transitions in $\mathrm{Li}_{x} \mathrm{WO}_{3}$. MicroRaman studies show systematic crystalline phase changes in the spectra of $\mathrm{WO}_{3}$ layers during $\mathrm{Li}^{+}$ion intercalation and deintercalation, which agree with the XRD data. These devices exhibit interesting optical modulation (up to 70\%) due to intercalation/deintercalation of $\mathrm{Li}$ ions into/from the $\mathrm{WO}_{3}$ layer of the devices as a function of applied coloration/bleaching voltages. The obtained optical modulation of the electrochromic devices indicates that, they are suitable for applications in electrochromic smart windows.

\section{Introduction}

Tungsten oxide $\left(\mathrm{WO}_{3}\right)$ has been one of the most widely studied materials due to its multifunctional properties that have wide spectrum of applications in electrochromic devices, catalysers, gas sensors, optical switching devices, and so forth [1-3]. Over the past three decades, intensive research has been carried out towards improving $\mathrm{WO}_{3}$-based electrochromic (EC) devices due to their important energy saving properties [4-7]. A typical asymmetric EC device consists of an ion conducting (IC) layer, which also acts

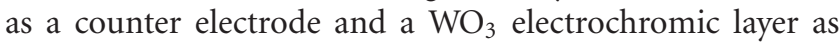
the working cathode, sandwiched between two transparent conductive electrodes (TEs) $[8,9]$. When a low voltage (1$3 \mathrm{~V}$ ) is applied across the TEs, $\mathrm{Li}^{+}$ions from the counter electrode and electrons $\left(\mathrm{e}^{-}\right)$from the TE move to the EC $\mathrm{WO}_{3}$ layer. This double injection results in the formation of colored $\mathrm{Li}_{x} \mathrm{WO}_{3}$ bronzes, with a controllable degree of coloration as a function of $x$ ( $\mathrm{Li}$ ion concentration). When the applied voltages are reversed, the $\mathrm{Li}^{+}$ions deintercalate, leading to a bleached state. The EC phenomenon, with $x \mathrm{e}^{-}$ and $\mathrm{Li}^{+}$ions inserted into (ejected out of) the system, can be represented as:

$$
\begin{aligned}
& \mathrm{WO}_{3}+x \mathrm{Li}^{+}+x \mathrm{e}^{-} \longleftrightarrow \mathrm{Li}_{x} \mathrm{WO}_{3} \\
& \text { clear } \\
& \text { dark blue }
\end{aligned}
$$

The performance of an EC device depends on the crystallinity, crystallite size, porosity, and thickness of the electrochromically active layer [10-14]. As far as the preparation of individual layers in an EC device is concerned, PVD techniques (thermal evaporation, sputtering, pulsed laser deposition) and mild chemical approaches such as sol-gel processes have been used [10-15]. Among these, the sol-gel technique is attractive. The sol-gel process allows a detailed control of the film texture and structure, leading to tailored electrochromic properties. Mesoporous $\mathrm{WO}_{3}$ films prepared by a sol-gel method with block copolymer templates have been investigated by Cheng et al. and by Djaoued et al. $[11,14]$. Macroporous $\mathrm{WO}_{3}$ films were also synthesized via 
sol-gel processing using polyethylene-glycol as a templating agent [12]. Mesoporous materials, due to their higher surface area, exhibit better kinetics for coloration and bleaching in comparison with standard sol-gel-derived $\mathrm{WO}_{3}$ thin films. On the other hand, macroporous $\mathrm{WO}_{3}$, which may have a wider range of applications as an ion hosting material, has displayed coloration efficiency values higher than those previously reported in the literature [12]. The motivation for synthesizing such porous materials emerges from the increased diffusion constant of intercalating ions by two orders of magnitude in porous EC-layer-based devices. Templating agents such as polyethyleneglycol (PEG), pluronic (P123), or organically modified silane (ORMOSIL) increase the porosity of the electrochromic layer $[8,9]$. In addition to that ORMOSIL has certain other advantages upon annealing, as the silane in the ORMOSIL provides a silica network which helps to prepare crack-free $\mathrm{WO}_{3}$ films. Crystalline phases of $\mathrm{WO}_{3}$ occur primarily in three forms: distorted cubic $\mathrm{ReO}_{3}$ structures, hexagonal, and pyrochlore. The distorted cubic $\mathrm{ReO}_{3}$ structure manifests itself, in monoclinic $(\mathrm{Pc})$, triclinic $(\mathrm{P} 1)$, monoclinic $(\mathrm{P} 21 / \mathrm{n})$, orthorhombic $(\mathrm{Pmnb})$, and tetragonal $(\mathrm{P} 4 / \mathrm{nmm})$ phases at various temperatures ranging from -263 to $900^{\circ} \mathrm{C}$, in increasing order of symmetry. Usually electrochromic studies have been performed on hexagonal (h), pyrochlore, and monoclinic $(\mathrm{m})$ phases as they are naturally stable or metastable at room temperature $[4,8,9,16,17]$. Another factor that influences the performance of the electrochromic devices is the nanostructures of $\mathrm{WO}_{3}$. A detailed study of electrochromic properties of nanostructured tungsten oxide with room temperature stable structure of $\mathrm{m}-\mathrm{WO}_{3}$, metastable structure of h- $\mathrm{WO}_{3}$, and titania-stabilized o- $\mathrm{WO}_{3}$ (higher temperature phase) has not been published until recently. Another interesting aspect is the phase changes that are associated with the electrochromic effect in crystalline $\mathrm{WO}_{3}$. Intercalation of $\mathrm{Li}$ into $\mathrm{ReO}_{3}$ type tungsten oxides transforms lower symmetry phases to the higher symmetry phases. This phase change has been studied by Raman spectroscopy or by XRD by many researchers [16-19].

When both Raman spectroscopy and XRD techniques are employed simultaneously, a detailed study of the intermediate structural changes in the $\mathrm{Li}_{x} \mathrm{WO}_{3}$ can be performed. These methods are practical for the device characterization as they can be performed nondestructively, they can probe the structural changes occurring in the EC layer and provide an estimate of the quantity of intercalated ions.

In this paper, we present a sol-gel methodology based on tungstic acid in the presence of ORMOSIL as a templating agent to prepare films of nanostructured hexagonal- $\mathrm{WO}_{3}$, nanostructured monoclinic- $\mathrm{WO}_{3}$, and titania-stabilized orthorhombic $\mathrm{WO}_{3}$ with mesomacroporous features. These phases have been stabilized as thin films and used as an active electrochromic layers for the construction of asymmetric electrochromic devices. A detailed micro-Raman spectroscopic structural characterization of Li ions intercalation/deintercalation into the $\mathrm{WO}_{3}$ layer of the operating EC devices as a function of applied coloration/bleaching voltages has been performed. Results of the XRD characterization of the structural changes occurring during the intercalation/deintercalation of $\mathrm{Li}$ ions into the $\mathrm{WO}_{3}$ layers of the operating EC device as a function of applied voltages are described. The optical transmittance data obtained in conjunction with the Raman and the XRD studies are presented to demonstrate the applicability of these materials for energy saving electrochromic smart windows.

\section{Experimental Details}

In order to obtain porous $\mathrm{WO}_{3}$ films with sufficient thickness, hybrid organically modified silicates (ORMOSIL) was used as a template precursor. It was prepared by an acylation reaction between poly(propylene glycol) bis(2-aminopropyl ether) (2-APPG) with isocyanatopropyltriethoxysilane (ICS) in tetrahydrofuran (THF) in the volume ratio $1: 0.1: 1[6,8$, 20].

2.1. Synthesis of $h-W O_{3}$ and $m-W O_{3}$. The sol-gel coating solutions used for the preparation of $\mathrm{h}-\mathrm{WO}_{3}$ and $\mathrm{m}-\mathrm{WO}_{3}$ films were synthesized according to the following procedures. $\mathrm{WO}_{3}$ sols were prepared by dissolving tungsten powder $(99.9 \%)$ in 35\% hydrogen peroxide. The mixture was left to stir at room temperature for 8 hours. After the addition of a small amount of ethanol (EtOH), the sol was refluxed for 4 hours at a temperature of $80^{\circ} \mathrm{C}$. Finally, $1.5 \mathrm{~g}$ of the hybrid ORMOSIL dissolved in EtOH was added dropwise into the $\mathrm{WO}_{3}$ sol and stirred for one hour. The final sol was used for the $\mathrm{WO}_{3}$ film coating. The $\mathrm{WO}_{3}$ films were deposited by dip coating onto $\mathrm{SiO}_{2}$-coated glass or indium tin oxide (ITO) coated-glass substrates with a surface resistivity of $5-15 \Omega / \mathrm{sq}$, at a controlled speed of $4 \mathrm{~mm} / \mathrm{s}$. After drying at $60^{\circ} \mathrm{C}$, the films were annealed at 400 and $500^{\circ} \mathrm{C}$ and were held at the peak temperature for one hour and then cooled to room temperature which resulted in $\mathrm{h}-\mathrm{WO}_{3}$ and $\mathrm{m}-\mathrm{WO}_{3}$, respectively.

2.2. Synthesis of $\mathrm{o}-\mathrm{WO}_{3}$. It has been a challenge to stabilize the higher symmetric phases of $\mathrm{WO}_{3}$ such as orthorhombic $(\mathrm{o})$, tetragonal $(\mathrm{t})$, and cubic (c) at room temperature, since $\mathrm{ReO}_{3}$-type $\mathrm{WO}_{3}$ reverts to $\mathrm{m}-\mathrm{WO}_{3}$, due to a second-order Jahn-teller distortion, irrespective of thermal treatment [21]. A two-stage process was adopted to prepare $\mathrm{o}-\mathrm{WO}_{3}$ thin films on ITO-coated glass substrates. The first stage involves the dip coating of a tungsten oxide film using the above described tungstic acid sol in the presence of ORMOSIL as a templating agent, followed by an annealing at $600^{\circ} \mathrm{C}$ for one hour, resulting in the formation of a porous $\mathrm{WO}_{3}$ thin film. In the second stage, the porous $\mathrm{WO}_{3}$ film was dip coated with a titanium-alkoxide-based ethanol solution containing ORMOSIL, followed by another annealing at $600^{\circ} \mathrm{C}$ to prepare $\mathrm{TiO}_{2}$-stabilized o- $\mathrm{WO}_{3}$ film.

2.3. Fabrication of EC Devices. We prepared several electrochromic devices with the configuration:

ITO-coated-glass-1/ $\mathrm{WO}_{3} / \mathrm{ICL} / \mathrm{ITO}$-coated-glass-2,

where ITO-coated-glass- 1 and ITO-coated-glass- 2 are the two transparent electrodes (TEs) used to apply the electric 


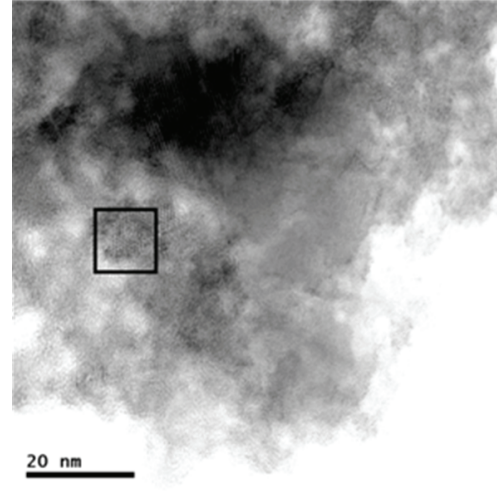

(a) $400^{\circ} \mathrm{C}$

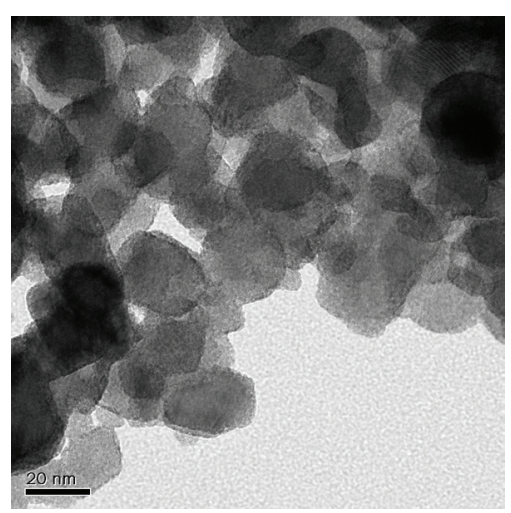

(b) $500^{\circ} \mathrm{C}$

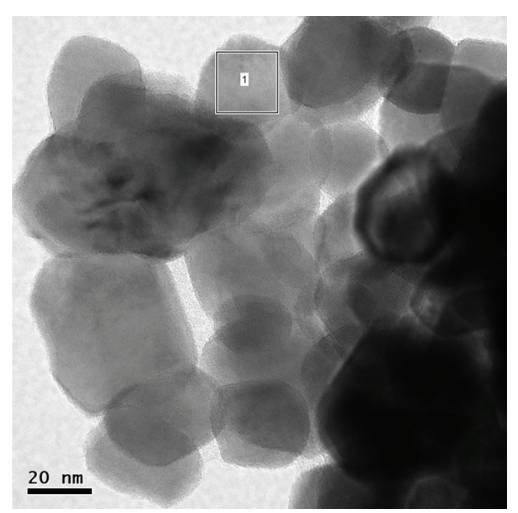

(c) $600^{\circ} \mathrm{C}$

Figure 1: Transmission electron micrographs of tungsten oxide films prepared at 400 (grain size $\sim 10 \mathrm{~nm}$ ), 500 (grain size $\sim 19 \mathrm{~nm}$ ), and $600^{\circ} \mathrm{C}$ (grain size $\sim 25 \mathrm{~nm}$ ).

field, $\mathrm{WO}_{3}$ is the electrochromic layer and ICL is the ion conducting and electronically insulating layer. The ICL is applied on top of the $\mathrm{WO}_{3}$ layer and the ITO-coatedglass-2 is gently pressed against this coating to ensure a uniform distribution of the ICL. After making the electrical connections, the EC device is ready for testing. The area of the $\mathrm{EC}$ devices was $5 \times 2.5 \mathrm{~cm}^{2}$.

\subsection{Structural and Optical Characterization}

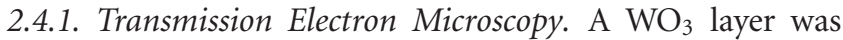
deposited onto a $\mathrm{SiO}_{2}$-coated glass substrate and annealed in air at 400,500 , or $600^{\circ} \mathrm{C}$ for one hour. TEM of the $\mathrm{WO}_{3}$ layers was performed on a small amount of film scrapped off the $\mathrm{SiO}_{2}$-coated glass substrate and placed into a glass vial. The sample was imaged using a 2011 JEOL STEM at $200 \mathrm{keV}$. Images were captured on a $4 \mathrm{k} \times 4 \mathrm{k}$ multiscan CCD camera using Digital Micrograph from Gatan.

2.4.2. Raman Spectroscopy. Raman spectra were recorded at room temperature with a Jobin-Yvon Labram HR microanalytical spectrometer equipped with a motorized xy stage and autofocus. The spectra were generated with $17 \mathrm{~mW}$, $632.8 \mathrm{~nm} \mathrm{He}-\mathrm{Ne}$ laser excitation and dispersed with the 1800 grooves $/ \mathrm{mm}$ grating across the $0.8 \mathrm{~m}$ length of the spectrograph. The laser power was $4 \mathrm{~mW}$ at the sample surface. The spectral resolution is estimated to be less than $0.5 \mathrm{~cm}^{-1}$ for a slit width of $150 \mu \mathrm{m}$ and a confocal hole of $300 \mu \mathrm{m}$.

2.4.3. X-Ray Diffraction (XRD). XRD measurements were carried out in reflection with a custom built theta-theta diffractometer equipped with pyrolytic graphite monochromator and analyzer crystals. $\mathrm{Cu} \mathrm{K}-\alpha$ radiation $(\lambda=$ $0.154178 \mathrm{~nm}$ ) was used for the measurements, and the data are shown as a function of the modulus of the scattering vector $q=4 \pi \lambda^{-1} \sin \theta$, where $2 \theta$ is the scattering angle. Air scattering was avoided by evacuating the sample space. We determine the lattice constants for different sample states by fitting the diffraction patterns. Each spectrum is fitted to a series of Gaussian peaks superimposed on an overall quadratic background. These fits, shown as lines in the figure, match the data points closely. The peak width, assumed to be the same for all reflections, and the intensities of the individual peaks are treated as fitting parameters. We correct the peak width for the instrument resolution and use it to estimate the crystallite size using the Scherrer method, assuming that for example, crystallite-to-crystallite variations of the lattice parameter do not contribute to the peak widths.

2.4.4. UV-VIS Spectrophotometery. The optical transmittance spectra of the EC devices in their colored/bleached states were recorded at normal incidence with a Biochrom Ultrospec 2000 UV-visible spectrophotometer.

\section{Results and Discussion}

3.1. Microstructure of the EC Layer Prepared at Different Temperatures. TEM of the $\mathrm{WO}_{3}$ layers was performed on a small amount of film scraped off the $\mathrm{SiO}_{2}$-coated glass substrate. Figure 1(a) shows the TEM image of the nanocrystalline $\mathrm{WO}_{3}$ annealed at $400^{\circ} \mathrm{C}$. The nanocrystalline nature is evident from the dimension of domain which is showing crystalline lattice. The interplanar distances obtained by inverse Fast Fourier transforms (FFTs) of lattice spacing shown in the region indicated by the box were found to be 0.72 and $0.79 \mathrm{~nm}$, respectively. These lattice spacings correspond to those of hexagonal $\mathrm{WO}_{3}\left(\mathrm{~h}-\mathrm{WO}_{3}\right)$ which are $a=0.7298(2) \mathrm{nm}, c=0.7798(3) \mathrm{nm}$. Figure $1(\mathrm{~b})$ shows the TEM image for the film annealed at $500^{\circ} \mathrm{C}$. The average crystallite size was found to be $19.3 \mathrm{~nm}$. The lattice spacings were determined by the FFT of the lattice fringes at two different points on the $\mathrm{WO}_{3}$ crystallites (not shown here) and are found to be 0.3658 and $0.3625 \mathrm{~nm}$, again matching $\mathrm{m}-\mathrm{WO}_{3}$. Figure $1(\mathrm{~b})$ also shows the mesoporous structure of the walls separating the macropores in the $\mathrm{WO}_{3}$ films. Figure 1(c) shows the TEM image of the similarly prepared 


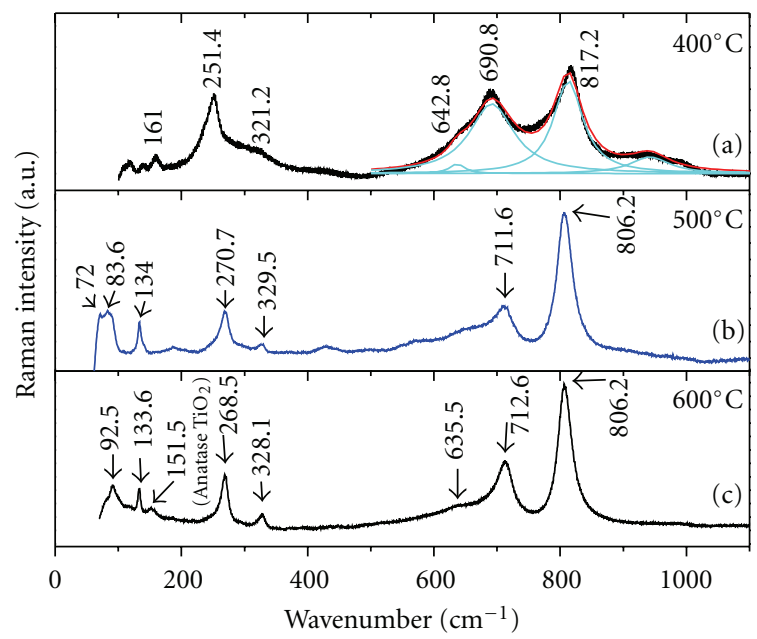

Figure 2: Micro-Raman spectra of tungsten oxide thin films prepared at $400,500,600^{\circ} \mathrm{C}$ indicating the formation of $\mathrm{h}-\mathrm{WO}_{3}$, $\mathrm{m}-\mathrm{WO}_{3}$, and $\mathrm{o}-\mathrm{WO}_{3}$.

sample. From the TEM image, it can be observed that the film is composed of $\mathrm{WO}_{3}$ nanocrystallites of an average size $\sim 25 \mathrm{~nm}$. The value of the interplanar distance is $0.3683 \mathrm{~nm}$, which is the lattice parameter $c$ of $\mathrm{m}-\mathrm{WO}_{3}$.

3.2. Crystalline Phases of the EC Layers Prepared at 400, 500, and $600^{\circ} \mathrm{C}$. Raman spectra of the $\mathrm{WO}_{3}$ film heat treated at 400 and $500^{\circ} \mathrm{C}$ are shown in Figures $2(\mathrm{a})$ and $2(\mathrm{~b})$. For the films heat treated at $400^{\circ} \mathrm{C}$, the bands below $200 \mathrm{~cm}^{-1}$ can be ascribed to lattice vibrations. The band observed at $251.4 \mathrm{~cm}^{-1}$ is assigned to $\delta(\mathrm{O}-\mathrm{W}-\mathrm{O})$ deformation vibrations, while the bands at 690.8 and $817.2 \mathrm{~cm}^{-1}$ are due to $\nu(\mathrm{O}$ $\mathrm{W}-\mathrm{O})$ stretching vibrations. These bands are characteristic features of $\mathrm{h}-\mathrm{WO}_{3}$. The Raman peak positions of our $\mathrm{h}-\mathrm{WO}_{3}$ films match those reported for $\mathrm{h}-\mathrm{WO}_{3}$ powder by Daniel et al. [21]. The bands at 817.2 and $690.8 \mathrm{~cm}^{-1}$ are broadened due to the nanocrystalline nature of the $\mathrm{h}-\mathrm{WO}_{3}$ films. Figure 2(b) shows the Raman spectrum of the films prepared at $500^{\circ} \mathrm{C}$. The $\mathrm{m}-\mathrm{WO}_{3}$ features are observed from the Raman peaks at $134.0 \mathrm{~cm}^{-1}$ (lattice mode), $270.7 \mathrm{~cm}^{-1} \delta(\mathrm{O}-\mathrm{W}-\mathrm{O})$, and $\nu(\mathrm{O}-\mathrm{W}-\mathrm{O})$ modes at 711.6 and $806.2 \mathrm{~cm}^{-1}$.

The Raman spectrum (Figure 2(c)) of the $\mathrm{WO}_{3}-\mathrm{TiO}_{2}$ composite film heat treated at $600^{\circ} \mathrm{C}$ shows peaks at 806.2, $712.6 \mathrm{~cm}^{-1}(\nu(\mathrm{O}-\mathrm{W}-\mathrm{O})), 328.1,268.5 \mathrm{~cm}^{-1}(\delta(\mathrm{O}-\mathrm{W}-\mathrm{O}))$, $133.6,92.5 \mathrm{~cm}^{-1}$ (lattice modes) and a low intensity peak at $151.5 \mathrm{~cm}^{-1}$. It is well known that the peak positions corresponding to the stretching vibrations of O-W-O bonds are the same for the triclinic, monoclinic, and orthorhombic phases of $\mathrm{WO}_{3}$, whereas their lattice vibrations in the range $70-100 \mathrm{~cm}^{-1}$ show a difference in the Raman spectra $[17,22]$. This is primarily due to the fact that the lattice vibrational bands arise from the $\left(\mathrm{W}_{2} \mathrm{O}_{2}\right)_{n}$ chains of $\mathrm{WO}_{3}$. As the low temperature phases of $\mathrm{WO}_{3}$ are less symmetric than the high-temperature phases, the lattice vibrations between 70 and $100 \mathrm{~cm}^{-1}$ in Figure 2(b) exhibit more Raman bands for the monoclinic phase (83.6, and $\left.72.0 \mathrm{~cm}^{-1}\right)$ and only one mode at $92.5 \mathrm{~cm}^{-1}$ for the orthorhombic phase (Figure 2(c)).

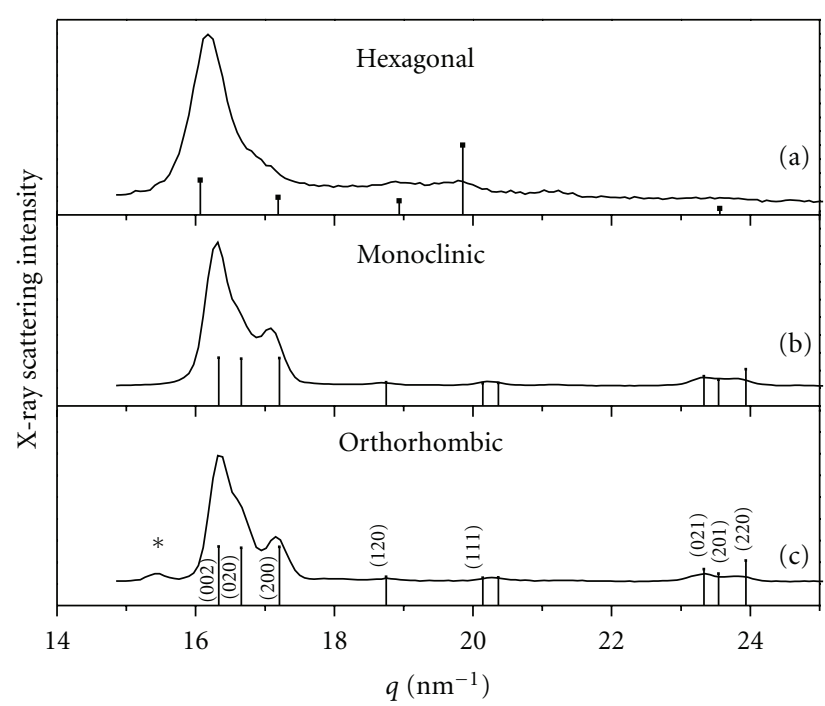

FIGURE 3: XRD patterns of tungsten oxide thin films prepared at $400,500,600^{\circ} \mathrm{C}$ indicating the formation of $\mathrm{h}-\mathrm{WO}_{3}, \mathrm{~m}-\mathrm{WO}_{3}$, and $\mathrm{o}-\mathrm{WO}_{3}$. The peak at $15.5 \mathrm{~nm}^{-1}$, indicated by ${ }^{*}$, is emerging from the ITO layer (c).

Pecquenard et al. have shown that o- $\mathrm{WO}_{3}$ can be crystallized at temperatures between 600 and $800^{\circ} \mathrm{C}$ using titanium oxide as structure stabilizer [22]. They reported the lattice vibrational mode of o- $\mathrm{WO}_{3}$ at $91 \mathrm{~cm}^{-1}$, which is similar to our result for the $\mathrm{WO}_{3}-\mathrm{TiO}_{2}$ composite film annealed at $600^{\circ} \mathrm{C}$

Figure 3(a) shows the $\mathrm{X}$-ray scattering of the $\mathrm{WO}_{3}$ layer, deposited on the ITO glass substrate and annealed at $400^{\circ} \mathrm{C}$ for one hour corresponds to hexagonal $\mathrm{WO}_{3}$, for which the JCPDS card 85-2460 diffraction pattern is shown by the vertical bars [23]. By fitting the diffraction pattern, we find the lattice constants of the hexagonal phase to be $a=$ $0.7379 \pm 0.0008$ and $c=0.7756 \pm 0.0002 \mathrm{~nm}$.

Figure 3(b) shows the diffraction pattern of the $\mathrm{WO}_{3}$ film heat treated at $500^{\circ} \mathrm{C}$. It matches with the JCPDS card $43-$ 1035 diffraction pattern of pure $\mathrm{m}-\mathrm{WO}_{3}$ (vertical bars). The lattice parameters obtained from the fitting of the diffraction pattern are $a=0.7351 \pm 0.0002, b=0.75396 \pm 0.0005$, $c=0.7712 \pm 0.0002 \mathrm{~nm}$, with $\beta=90.3^{\circ}$. Although the peaks are similar in Figures 3(b) and 3(c), the lattice parameters obtained from the fitting for the sample annealed at $600^{\circ} \mathrm{C}$ are $a=0.7351 \pm 0.0019, b=0.7566 \pm 0.0019$, and $c=$ $0.7724 \pm 0.0021 \mathrm{~nm}$, with $\beta=90^{\circ}$ indicating that the $\mathrm{WO}_{3}$ is in the orthorhombic phase.

\subsection{Construction of Asymmetric Electrochromic Devices Based} on $h-W O_{3}, m-W O_{3}$, and $o-W O_{3}$ Layers. In this section we describe the construction of asymmetric EC devices by using the thus synthesised $\mathrm{h}-\mathrm{WO}_{3}, \mathrm{~m}-\mathrm{WO}_{3}$, and o- $\mathrm{WO}_{3}$ thin films as the active electrochromic layer. The asymmetric EC device consists of an ion conductor layer, which also acts as a counter electrode and a $\mathrm{WO}_{3} \mathrm{EC}$ layer as the working cathode. These are sandwiched between two transparent conductive electrodes. As a low voltage is applied across the 


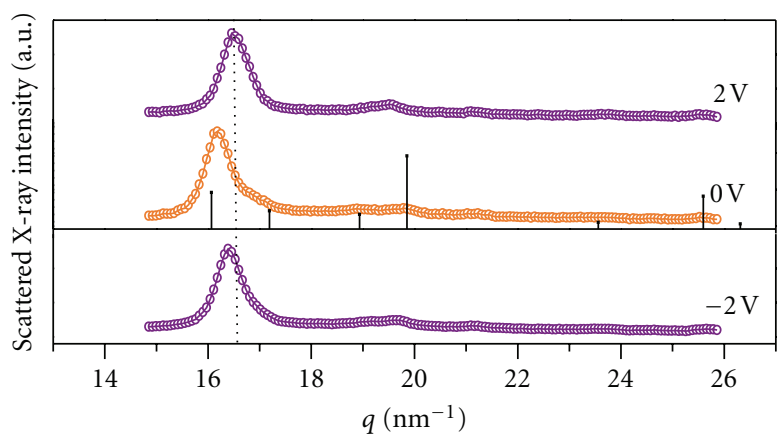

(a)

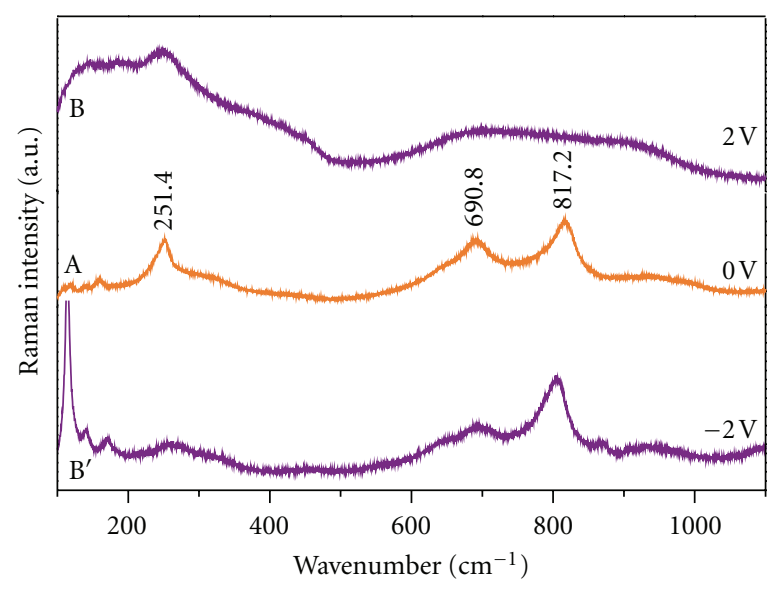

(b)

FIGURE 4: Electrochromic structural changes in the EC device constructed using $\mathrm{h}-\mathrm{WO}_{3}$ layer.

transparent conductors $(1-3 \mathrm{~V})$, ions move from the counter electrode and electrons from the transparent electrode to the EC layer to trigger a color change. The EC phenomenon occurring with such double injection can be represented as:

$$
\begin{aligned}
& \mathrm{WO}_{3}+x \mathrm{Li}^{+}+x \mathrm{e}^{-} \longleftrightarrow \mathrm{Li}_{x} \mathrm{WO}_{3} \\
& \text { clear }
\end{aligned}
$$

where $x$ electrons $\left(\mathrm{e}^{-}\right)$and lithium ions $\left(\mathrm{Li}^{+}\right)$are inserted into or ejected from the system. Reversing the voltage restores the device to its previous clear (bleached) optical state. The ion conducting layer is a gel which is prepared by mixing lithium iodide (LiI) and iodine $\left(\mathrm{I}_{2}\right)$ in an ethanol solution with ORMOSIL. A network of silanes, present in ORMOSIL, acts as the ion storage layer. This ion conducting layer supplies $\mathrm{Li}^{+}$ions to the EC layer under proper biasing. This layer is applied on top of the $\mathrm{WO}_{3}$ layer and another ITOcoated glass substrate is gently pressed against the ICL gel. The transparent conductive electrode (ITO layer) is $190 \pm$ $40 \mathrm{~nm}$ thick. The thickness of the $\mathrm{WO}_{3}$ layer used in the EC device was of $842 \pm 50 \mathrm{~nm}$. The $12 \pm 1 \mu \mathrm{m}$ thick ICL is sandwiched between the $\mathrm{WO}_{3}$ layer and a second ITO coatedglass slide. Then the device is connected to the leads, and it is ready for the testing.

3.4. Electrochromic Structural Studies during Intercalation (Deintercalation) of $\mathrm{Li}^{+}$Ions into (Ejected out of) the $h-\mathrm{WO}_{3}$ Layer of the EC Device. Figure 4 shows the XRD pattern (a) and the Raman spectrum (b) of the EC device constructed by using the $\mathrm{h}-\mathrm{WO}_{3}$ layer as an active working layer, in its colored and bleached states for applied potentials of 0.0 and $\pm 2.0 \mathrm{~V}$. Inserting and extracting lithium at $\pm 2.0 \mathrm{~V}$ shift the diffraction peak positions as seen in the figure. The lattice parameters of the $\mathrm{WO}_{3} \mathrm{EC}$ layer at $0 \mathrm{~V}$ are $a=$ $0.7379 \pm 0.0008$ and $c=0.7756 \pm 0.0002 \mathrm{~nm}$. We note that the lattice parameter $c$ decreases to $0.76152 \pm 0.0003$ during the sequence of measurements. The observed variations in the lattice parameters of $\mathrm{h}-\mathrm{WO}_{3} \mathrm{EC}$ layer upon lithiation are compared in the Table 1 . The lattice parameter $a$ remains initially the same, indicating that the unit cell volume decreases as the device ages during cycling. With an applied voltage of $\pm 2.0 \mathrm{~V}$, we observe that the lattice constant $c$ is significantly lower for the Li-intercalated state (positive voltage) and that $c$ increases as the lithium ions are extracted. The crystallite size remains generally close to $10 \mathrm{~nm}$, with a possible slight increase during the measurement sequence.

Raman spectra show strong changes in the stretching bands. Figure 4(b)A shows the Raman spectrum of the pure $\mathrm{h}-\mathrm{WO}_{3}$ layer. The bands located at $251.4 \mathrm{~cm}^{-1}$, due to $\delta(\mathrm{O}-$ $\mathrm{W}-\mathrm{O})$, and at 690.8 and $817.2 \mathrm{~cm}^{-1}$ due to the $v(\mathrm{O}-\mathrm{W}-$ $\mathrm{O})$, are the characteristic Raman modes of the h- $\mathrm{WO}_{3}$. By applying a potential of $2.0 \mathrm{~V}$ across the device, $\mathrm{Li}$ ions are intercalated from ICL into the $\mathrm{h}-\mathrm{WO}_{3}$ layer. Figure $4(\mathrm{~b}) \mathrm{B}$ shows the Raman spectrum of the EC device in its colored state after applying a voltage of $2.0 \mathrm{~V}$. It can be seen that upon $\mathrm{Li}$ intercalation at this potential, the modes due to the $\nu(\mathrm{O}-\mathrm{W}-\mathrm{O})$ stretching vibrations disappear. Correspondingly, by reversing the potential $(-2.0 \mathrm{~V})$, the device reverts to its previous bleached state by deintercalating Li (Figure $4(\mathrm{~b}) \mathrm{B}^{\prime}$ ), clearly demonstrating the structural reversibility of the active layer of the EC device.

A striking difference in the Raman spectra of $\mathrm{h}-\mathrm{Li}_{x} \mathrm{WO}_{3}$ is the vanishing of bands at the applied coloration potentials of $2.0 \mathrm{~V}$, although XRD pattern showed no structural transition. In order to understand the vanishing of the stretching $v(\mathrm{O}$ $\mathrm{W}-\mathrm{O}$ ) modes in the Raman spectra (Figure 4(b)B), while the EC active layer remains $\left(\mathrm{h}-\mathrm{Li}_{x} \mathrm{WO}_{3}\right)$ we consider the $\mathrm{Li}^{+}$occupancy for the applied potential of $2.0 \mathrm{~V}$. In this scenario, Li ions inside the hexagonal windows (HW) start moving towards the four coordinated square window (SW) in order to accommodate the additional Li ions [9]. Hibino et al. have suggested that the location of $\mathrm{Li}$ ion near the $\mathrm{SW}$ is governed by the Li-Li ionic distances and the distance between the SW [24]. As there is no shielding for the $\mathrm{Li}$ ions and the Li-Li ionic distance is more than $5.5 \AA$, Li ions can only occupy alternate sites close to SW. This leads to ordering of $\mathrm{Li}$ ions inside the $\mathrm{h}-\mathrm{WO}_{3}$. Hibino et al. have mentioned that for $\mathrm{Li} / \mathrm{W}$ ratios $>0.4$, the SWs of the $\mathrm{h}-\mathrm{WO}_{3}$ 
TABLE 1: The lattice parameters of $\mathrm{WO}_{3} \mathrm{EC}$ layer prepared at 400,500 , and $600^{\circ} \mathrm{C}$ and the lattice parameters after lithiating the sample at $+2.0 \mathrm{~V}$.

\begin{tabular}{|c|c|c|c|c|c|c|}
\hline \multirow{3}{*}{ S. No. } & \multirow{3}{*}{ Sample name } & \multirow{3}{*}{ Coloration voltage } & \multicolumn{4}{|c|}{ Lattice parameter } \\
\hline & & & & $\mathrm{nm}$ & & Angle \\
\hline & & & $a$ & $b$ & $c$ & $\beta$ \\
\hline \multirow{2}{*}{1} & \multirow{2}{*}{$400^{\circ} \mathrm{C}$ (Hexagonal) } & $0 \mathrm{~V}$ & $0.7379 \pm 0.0008$ & - & $0.7756 \pm 0.0002$ & - \\
\hline & & $+2 \mathrm{~V}$ & $0.74118 \pm 0.0012$ & & $0.76152 \pm 0.0003$ & \\
\hline \multirow{2}{*}{2} & \multirow{2}{*}{$500^{\circ} \mathrm{C}$ (Monoclinic) } & $0 \mathrm{~V}$ & $0.7351 \pm 0.0002$ & $0.7540 \pm 0.0005$ & $0.7712 \pm 0.00019$ & $90.3 \pm 0.6$ \\
\hline & & $+2 \mathrm{~V}$ & $0.7397 \pm 0.0015$ & $0.7418 \pm 0.002$ & $0.7717 \pm 0.0002$ & $89.6 \pm 10.1$ \\
\hline \multirow{2}{*}{3} & \multirow{2}{*}{$600^{\circ} \mathrm{C}$ (Orthorhombic) } & $0 \mathrm{~V}$ & $0.7351 \pm 0.0019$ & $0.7566 \pm 0.0019$ & $0.7724 \pm 0.0021$ & 90.0 \\
\hline & & $+2 \mathrm{~V}$ & $0.7445 \pm 0.0023$ & $0.7469 \pm 0.0058$ & $0.7624 \pm 0.0055$ & 90.0 \\
\hline
\end{tabular}

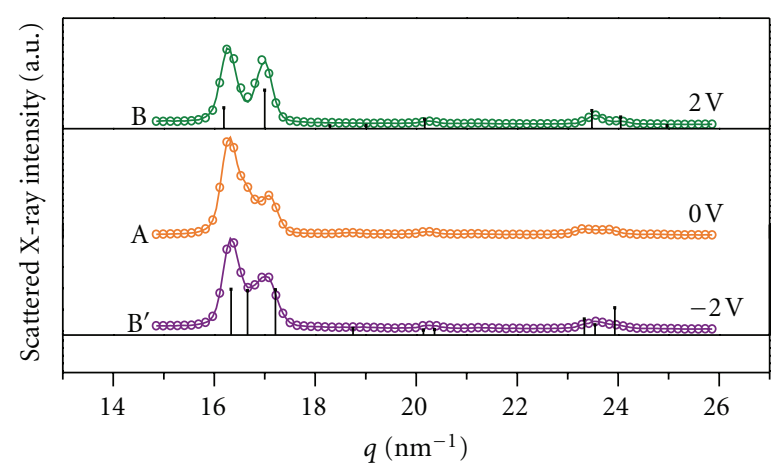

(a)

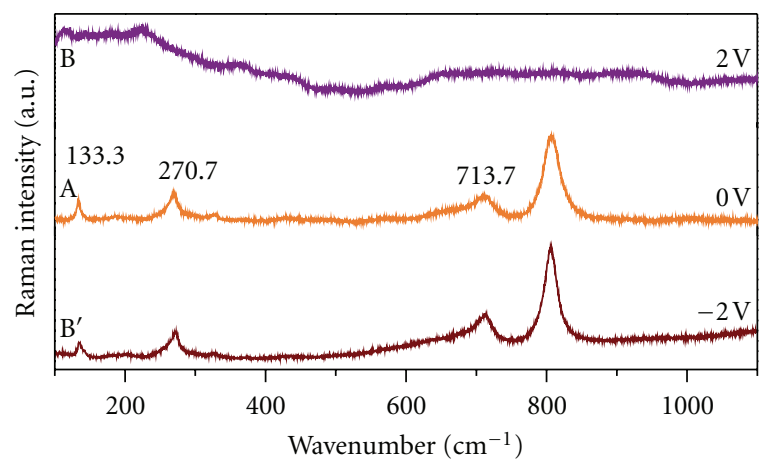

(b)

FIGURE 5: Electrochromic structural changes in the EC device constructed using $\mathrm{m}-\mathrm{WO}_{3}$ layer.

structure start to be occupied. In our case this happens when a coloration voltage of $2.0 \mathrm{~V}$ is applied to the EC device [24]. $\mathrm{h}-\mathrm{WO}_{3}$ is constituted by $\mathrm{WO}_{6}$ octahedrons. The ab plane in $\mathrm{WO}_{6}$ is already nearly symmetric. When $\mathrm{Li}$ is inserted into the square windows, the axial oxygen is also symmetrized, which results in isostructural $\mathrm{WO}_{6}$ octahedra as in the cubic$\mathrm{ReO}_{3}$ structure. For this type of structure vibrations are not Raman active. Hence Raman modes vanish for the Li ion intercalation at a coloration potential of 2.0. A detailed account on the structural transformation of $\mathrm{h}-\mathrm{Li}_{x} \mathrm{WO}_{3}$ is presented elsewhere [9].

\subsection{Electrochromic Structural Studies during Intercalation} (Deintercalation) of $\mathrm{Li}^{+}$Ions into (Ejected out of) the $\mathrm{m}-\mathrm{WO}_{3}$ Layer of the EC Device. Figure 5 shows the XRD pattern (a) and the Raman spectra (b) of the EC device constructed by using the $\mathrm{m}-\mathrm{WO}_{3}$ layer as an active working layer, in its colored and bleached states for applied potentials of 0.0 and $\pm 2.0 \mathrm{~V}$. The X-ray scattering of the $\mathrm{Li}_{x} \mathrm{WO}_{3}$ layer of the EC device based on the $\mathrm{m}-\mathrm{WO}_{3}$ layer is shown in Figure 5(a) as a function of the applied voltage. The diffraction pattern of the pure $\mathrm{m}-\mathrm{WO}_{3}$ layer, for which the JCPDS card 431035 diffraction pattern is represented by the vertical bars, is shown in Figure $5(\mathrm{a}) \mathrm{B}^{\prime}$. We determine the lattice constants $a, b$, and $c$ and the angle $\beta$ of the monoclinic phase for different sample states by fitting the diffraction patterns shown in Figure 5(a). The XRD pattern of the pure m$\mathrm{WO}_{3}$ layer has the lattice parameter $a=0.7351 \pm 0.0002$, $b=0.75396 \pm 0.0005, c=0.7712 \pm 0.0002 \mathrm{~nm}$, with $\beta=$ $90.3^{\circ}$. As the coloration voltages were applied, the XRD peaks change in the position and in the intensities indicating a structural transition associated with intercalation of Li. When a coloration potential of $2.0 \mathrm{~V}$ is applied, the $a$ and $b$ lattice parameters converge to a value of $0.7412 \mathrm{~nm}$, while $c$ parameter is $0.77165 \mathrm{~nm}$. The XRD pattern of the $\mathrm{Li}_{x} \mathrm{WO}_{3}$ after $\mathrm{Li}$ intercalation resembles that of the tetragonal $\mathrm{WO}_{3}$ crystalline phase (JCPDS 89-1287). The phase transition from $\mathrm{m}-\mathrm{WO}_{3}$ to tetragonal $\mathrm{Li}_{x} \mathrm{WO}_{3}\left(\mathrm{t}-\mathrm{Li}_{x} \mathrm{WO}_{3}\right)$ is obtained. It should be noted that, when the Li ions are deintercalated by applying reverse potential, the crystalline structure of $\mathrm{m}$ $\mathrm{WO}_{3}$ layer reverts back to the initial monoclinic lattice as shown in Figure $5(\mathrm{a})\left(\mathrm{B}^{\prime}\right)$. The observed variations in the lattice parameters of $\mathrm{m}-\mathrm{WO}_{3} \mathrm{EC}$ layer upon lithiation are compared in the Table 1.

Figure 5(b) A shows the Raman spectrum of the pure $\mathrm{m}-\mathrm{WO}_{3}$ layer. The Raman peaks at 713.7 and $806.2 \mathrm{~cm}^{-1}$, attributed to $\nu(\mathrm{O}-\mathrm{W}-\mathrm{O})$ modes of $\mathrm{m}-\mathrm{WO}_{3}$, were followed during the EC coloration and bleaching at $\pm 2.0 \mathrm{~V}$. Figure $5(\mathrm{~b}) \mathrm{B}$ shows the Raman spectrum of the $\mathrm{m}-\mathrm{WO}_{3}$ layer, coloured at $2.0 \mathrm{~V}$. The Raman modes due to $\nu(\mathrm{O}-\mathrm{W}-\mathrm{O})$ vanish completely. It has been observed from our previous work on $\mathrm{XRD}$ of $\mathrm{Li}_{x} \mathrm{WO}_{3}$ layer that for the applied coloration potential of $1.0 \mathrm{~V}$, the lattice parameter $c$ decreases from $0.77418 \pm 0.0002 \mathrm{~nm}$ to $0.7717 \pm 0.00015 \mathrm{~nm}$. At the same time, the lattice parameters $a(=0.7397 \pm 0.00145 \mathrm{~nm})$ and $b$ $(=0.7418 \pm 0.0021 \mathrm{~nm})$ converge to a same value within the 


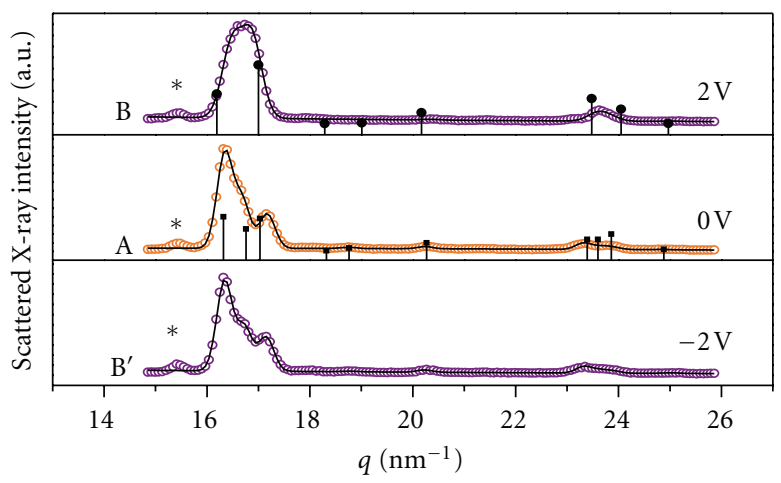

(a)

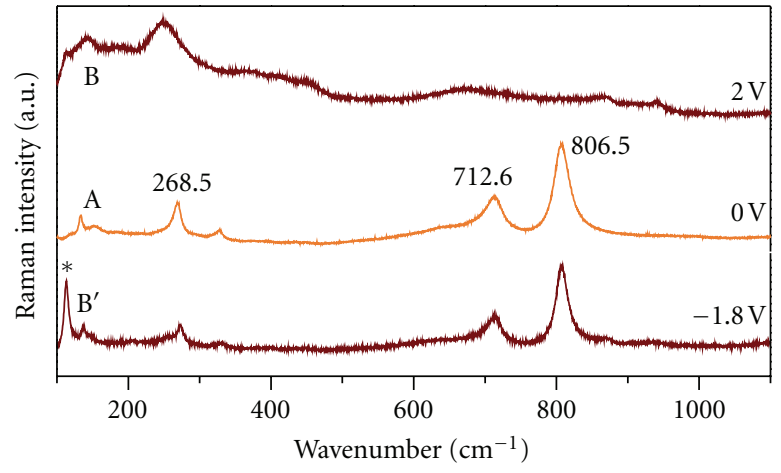

(b)

FIGURE 6: Electrochromic structural changes in the EC device constructed using o- $\mathrm{WO}_{3}$ layer.

experimental error. This tendency of $c$ to converge towards $a$ and $b$ indicates that the system is moving towards a cubic phase as the amount of intercalated $\mathrm{Li}$ is increased. The vanishing of the Raman mode is also attributed to this trend of $\mathrm{Li}_{x} \mathrm{WO}_{3}$ system to move towards cubic phase. It has been reported that the cubic $\mathrm{Li}_{x} \mathrm{WO}_{3}$ phase was obtained for $x>0.5[5,16]$. In our case, $\mathrm{Li}$ intercalation into $\mathrm{WO}_{3}$ at $2.0 \mathrm{~V}$ is not sufficient to reach cubic phase, whereas a higher symmetric state than that of the tetragonal phase is clearly observed. This indicates that for the applied potential of $2.0 \mathrm{~V}$ the amount of $\mathrm{Li}$ that has intercalated into $\mathrm{m}-\mathrm{WO}_{3}$ is between 0.23 and 0.5 . The complete vanishing of $v(\mathrm{O}-\mathrm{W}-\mathrm{O})$ Raman modes observed at a coloration potential of $+2.0 \mathrm{~V}$ is attributed to a phase transition to a higher symmetric state than that of $\mathrm{t}-\mathrm{Li}_{x} \mathrm{WO}_{3}$. Also, it is possible that atomic displacement within the unit cell could take place with the same lattice parameters, as Raman spectroscopy is sensitive even to a small change in the lattice parameters. Figure $5(\mathrm{~b}) \mathrm{B}^{\prime}$ shows the Raman spectrum of the $\mathrm{m}-\mathrm{WO}_{3}$ layer of the $\mathrm{EC}$ device after the deintercalation of $\mathrm{Li}$ at $-2.0 \mathrm{~V}$. The recorded Raman spectra exhibit the spectral features of the initial pure $\mathrm{m}-\mathrm{WO}_{3}$ layer (Figure 5(b)A). This demonstrates the structural EC reversibility of the system.

3.6. Electrochromic Structural Studies during Intercalation (Deintercalation) of $\mathrm{Li}^{+}$Ions into (out of) the $\mathrm{o}-\mathrm{WO}_{3}$ Layer of an EC Device. Figure 6(a) shows the X-ray scattering of the $\mathrm{Li}^{+}$intercalated/deintercalated $\mathrm{o}-\mathrm{WO}_{3}$ layer in a working EC device for applied potentials of $\pm 2.0 \mathrm{~V}$. The differences in the positions and intensity of the diffraction lines observed in Figure 6(a) show the structural changes associated with $\mathrm{Li}$ ion intercalation/deintercalation. The XRD pattern of $\mathrm{Li}$ ion deintercalated state is similar to that of the $\mathrm{o}-\mathrm{WO}_{3}$ state at $0 \mathrm{~V}$. The lattice parameters of the $\mathrm{o}-\mathrm{WO}_{3}$ layer calculated from the fitting of the XRD patterns are $a=0.7351 \pm 0.0019$, $b=0.7566 \pm 0.0019$, and $c=0.7724 \pm 0.0021 \mathrm{~nm}$, with $\beta=90^{\circ}$. Upon applying a coloration potential of $2.0 \mathrm{~V}$, a transition to the $\mathrm{t}-\mathrm{Li}_{x} \mathrm{WO}_{3}$ phase is obtained. At this potential, the lattice parameters $a$ and $b$ attain about the same value $(a=0.7445 \pm 0.0023, b=0.7469 \pm 0.0058 \mathrm{~nm})$, whereas $c$ is reduced to $0.7624 \pm 0.0055 \mathrm{~nm}$. The observed variations in the lattice parameters of titania stabilized o- $\mathrm{WO}_{3}$ EC layer, upon lithiation, are compared in the Table 1. This observed structural change is consistent with the well-established Li-induced phase transitions of lowto high-symmetric phases in $\mathrm{ReO}_{3}$-type tungsten oxides $[16,17,19]$. Upon lithium intercalation, the low-symmetry phases of $\mathrm{WO}_{3}$, such as triclinic and monoclinic, transform to higher symmetry structures such as tetragonal and cubic $[16,17,19]$. In this work, upon lithium ion intercalation, we have observed the phase transition from $\mathrm{o}-\mathrm{WO}_{3}$ to $\mathrm{t}$ $\mathrm{Li}_{x} \mathrm{WO}_{3}$, the next higher symmetric phase. In this tetragonal phase the "ab" plane of the $\mathrm{WO}_{6}$ octahedron is symmetric, a transformation induced by $\mathrm{Li}$ ion intercalation at $2.0 \mathrm{~V}$. At this potential, the $\mathrm{Li}$ ion concentration is 0.226 and a complete phase transformation to the $\mathrm{t}-\mathrm{Li}_{x} \mathrm{WO}_{3}$ is achieved. These values of $\mathrm{Li}$ ion concentrations for the observed phases are consistent with the values reported by other authors $[16,19]$. The phase transition as a function of the applied potential occurs gradually from $\mathrm{o}-\mathrm{WO}_{3}$ to $\mathrm{t}-\mathrm{Li}_{x} \mathrm{WO}_{3}$ with a tendency for a phase transition towards a cubic $\mathrm{Li}_{x} \mathrm{WO}_{3}$, as the concentration of the inserted Li ions increases from 0.090 to 0.226 .

Figure 6(b) shows the Raman spectra of the $\mathrm{o}-\mathrm{WO}_{3}$ layer in a working EC device as a function of applied voltage. When a coloration potential of $2.0 \mathrm{~V}$ is applied, all the O-W-O stretching modes vanish (Figure 6(b)B), as expected for the more symmetric phases. The XRD analysis shows that the phase transition occurs gradually, and it is impossible to clearly identify the phase of the $\mathrm{Li}_{x} \mathrm{WO}_{3}$; since the lattice parameters are changing continuously as a function of applied potential or in other words, as a function of the amount of intercalated Li ions. The Raman spectrum in Figure 6(b)B shows no O-W-O stretching modes due to the fact that the structure of the $\mathrm{o}-\mathrm{WO}_{3}$ layer is gradually becoming more symmetric. In a previous work, we have shown that for higher voltages such as $3.0 \mathrm{~V}$, the $\mathrm{Li}_{x} \mathrm{WO}_{3}$ attains a cubic phase when starting from the m$\mathrm{WO}_{3}$ phase and that all the Raman modes vanished [5]. Figure $6(\mathrm{~b}) \mathrm{B}^{\prime}$ show that the $\mathrm{o}-\mathrm{WO}_{3}$ crystalline structure is recovered, when the coloring voltage is reversed $(-2.0 \mathrm{~V})$, demonstrating the reversibility of the device. The detailed report on the performance of the $\mathrm{o}-\mathrm{WO}_{3}$ layer as $\mathrm{EC}$ active layer is presented in our previous paper [25]. 


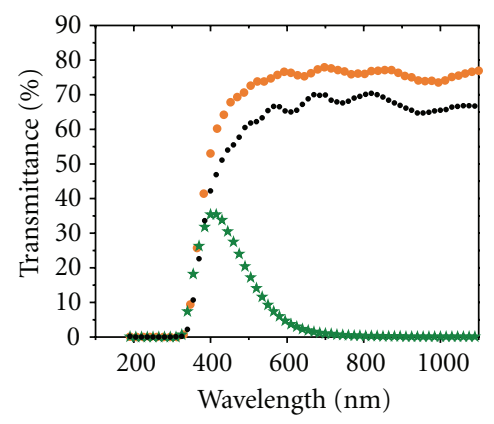

(a)

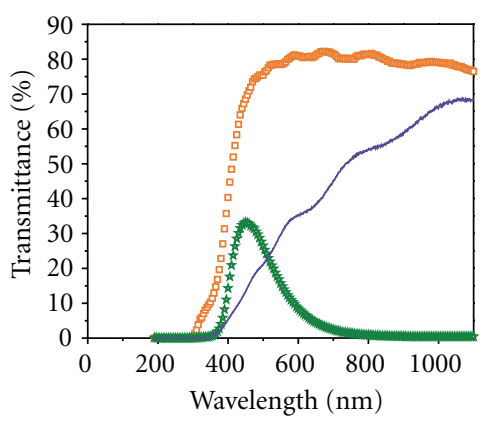

(b)

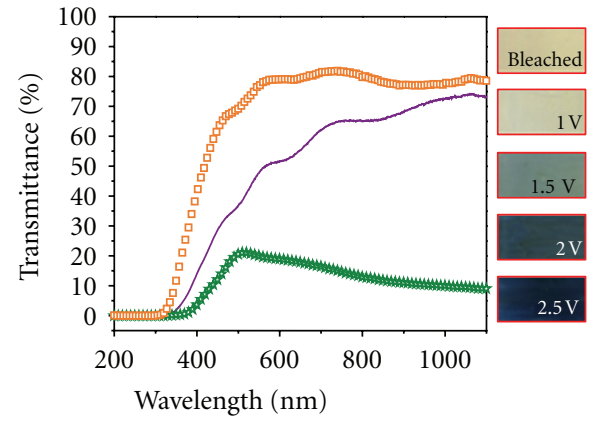

(c)

FIGURE 7: Transmission spectra of the EC devices constructed using $\mathrm{h}-\mathrm{WO}_{3}, \mathrm{~m}-\mathrm{WO}_{3}$, and $\mathrm{o}-\mathrm{WO}_{3}$ in the as prepared state, at coloration potential of $2.5 \mathrm{~V}$ and at bleaching potential of $-1.0 \mathrm{~V}$. The photos show the visible coloration to the naked eye when the EC devices are colored at various coloration potential. The photos represent typically the $\mathrm{EC}$ device based on $\mathrm{m}-\mathrm{WO}_{3}$.

3.7. Optical Studies of the Electrochromic Devices Based on the $h-W O_{3}, m-W O_{3}$, and $o-W O_{3}$ Layers. The optical transmittance of the EC device constructed by using the h$\mathrm{WO}_{3}$, layer in its colored and bleached states for an applied coloration potential of $2.5 \mathrm{~V}$ and at bleaching potential of $-1.0 \mathrm{~V}$ is shown in Figure $7(\mathrm{a})$. The recorded transmission spectra of the device in the bleached state for potentials at $-2.5 \mathrm{~V}$ are indistinguishable from the spectrum of the device bleached at $-1.0 \mathrm{~V}$ (hence not shown), clearly demonstrating the reversibility of the device. In the bleached state, the transmittance of the device at a wavelength $1100 \mathrm{~nm}$ was $76.9 \%$. At $+2.5 \mathrm{~V}$ the transmittance is reduced $0.1 \%$. When the coloration potentials of $+2.5 \mathrm{~V}$ are applied, the maximum transmittance is observed at $403.5 \mathrm{~nm}$, and the transmittance FWHM is $147.0 \mathrm{~nm}$. The optical modulation of $\sim 76 \%$ above $800 \mathrm{~nm}$ obtained here is exceptionally high for EC devices [26]. Figure 7(b) shows the optical transmittance spectra of a $\mathrm{m}-\mathrm{WO}_{3}$-(prepared at $500^{\circ} \mathrm{C}$ ) based EC device in bleached state $(-1.0 \mathrm{~V})$ and coloured at $+2.5 \mathrm{~V}$. In the bleached state, the transmittance of the device at $1100 \mathrm{~nm}$ was $76.4 \%$. At the coloration potential of $+2.5 \mathrm{~V}$ the transmittance was reduced to $0.0 \%$. The device exhibits an optical modulation of $76.1 \%$. Figure 7 (c) shows the transmission spectra of the $\mathrm{o}-\mathrm{WO}_{3}$, based EC device in its colored and bleached states. In the bleached state the transmittance at a wavelength of $1100 \mathrm{~nm}$ was $78.5 \%$. At a coloration potential of $+2.5 \mathrm{~V}$ the corresponding transmittance is reduced to $9.1 \%$. The actual digital photograph images of the device in the bleached and colored states for the device prepared using $\mathrm{m}-\mathrm{WO}_{3}$ (i.e, EC layer prepared at $500^{\circ} \mathrm{C}$ ) are also presented in Figure 7. The optical modulation of about $\sim 70 \%$ or more obtained in the EC devices constructed in this work is highly desirable for practical applications in electrochromic smart windows. Further, the transmittance of the mesomacroporous $\mathrm{WO}_{3}$ layer (solid line) is lower than the bleached transmission spectrum of the device, which is attributed to the volume scattering in the film due to the microstructure [27].

\section{Summary}

Various mesomacroporous, crack-free, nanocristalline (NC) $\mathrm{WO}_{3}$ thin films up to $\sim 850 \mathrm{~nm}$ thick were prepared using tungstic acid as a precursor and ORMOSIL as a templating agent. Pure h- $\mathrm{WO}_{3} \mathrm{NC}$ films with crystallite size of $\sim 10 \mathrm{~nm}$ were obtained after calcination at $400^{\circ} \mathrm{C}$. Pure $\mathrm{m}-\mathrm{WO}_{3}$ films with crystallite size of $\sim 16 \mathrm{~nm}$ were synthesized after annealing at $500^{\circ} \mathrm{C} . \mathrm{o}^{-} \mathrm{WO}_{3}$ thin films, stabilized by $\mathrm{NC}$ anatase $\mathrm{TiO}_{2}$, are obtained by a sol-gel-based two-stage dip coating method and subsequent annealing at $600^{\circ} \mathrm{C}$. Thus prepared $\mathrm{WO}_{3}$ films on ITO coated glass substrate were used as the active EC layer for the construction of various asymmetric EC devices. Coloration and bleaching of the EC devices were achieved by intercalating and deintercalating $\mathrm{Li}$ into the $\mathrm{WO}_{3}$ layers at coloration potential of $2.5 \mathrm{~V}$ and at bleaching potential of $-1.0 \mathrm{~V}$. The EC devices based on $\mathrm{h}-\mathrm{WO}_{3}, \mathrm{~m}-\mathrm{WO}_{3}$, and o- $\mathrm{WO}_{3}$ as $\mathrm{EC}$ active layers exhibit an exceptionally high optical modulation of $70 \%$ and qualify the device for EC smart window applications.

\section{Acknowledgment}

The financial support of the National Science and Engineering Research Council (NSERC) of Canada is gratefully acknowledged.

\section{References}

[1] E. Rossinyol, A. Prim, E. Pellicer et al., "Synthesis and characterization of chromium-doped mesoporous tungsten oxide for gas-sensing applications," Advanced Functional Materials, vol. 17, no. 11, pp. 1801-1806, 2007.

[2] T. He and J. Yao, "Photochromic materials based on tungsten oxide," Journal of Materials Chemistry, vol. 17, no. 43, pp. 4547-4557, 2007.

[3] C. G. Granqvist, “Out of a niche," Nature Materials, vol. 5, no. 2, pp. 89-90, 2006.

[4] S. K. Deb, "Opportunities and challenges in science and technology of $\mathrm{WO}_{3}$ for electrochromic and related applications," Solar Energy Materials and Solar Cells, vol. 92, no. 2, pp. 245258, 2008.

[5] C. G. Granqvist, "Electrochromic tungsten oxide films: review of progress 1993-1998," Solar Energy Materials and Solar Cells, vol. 60 , no. 3, pp. 201-262, 2000. 
[6] E. Stathatos, P. Lianos, U. Lavrencic-Stangar, and B. Orel, "A high-performance solid-state dye-sensitized photoelectrochemical cell employing a nanocomposite gel electrolyte made by the sol-gel route," Advanced Materials, vol. 14, no. 5, pp. 354-357, 2002.

[7] P. R. Somani and S. Radhakrishnan, "Electrochromic materials and devices: present and future," Materials Chemistry and Physics, vol. 77, no. 1, pp. 117-133, 2003.

[8] S. Balaji, A.-S. Albert, Y. Djaoued, and R. Brüning, "MicroRaman spectroscopic characterization of a tunable electrochromic device for application in smart windows," Journal of Raman Spectroscopy, vol. 40, no. 1, pp. 92-100, 2009.

[9] S. Balaji, Y. Djaoued, A.-S. Albert, R. Z. Ferguson, and R. Brüning, "Hexagonal tungsten oxide based electrochromic devices: spectroscopic evidence for the Li ion occupancy of four-coordinated square windows," Chemistry of Materials, vol. 21, no. 7, pp. 1381-1389, 2009.

[10] S.-H. Baeck, K. S. Choi, T. F. Jaramillo, G. D. Stucky, and E. W. McFarland, "Enhancement of photocatalytic and electrochromic properties of electrochemically fabricated mesoporous $\mathrm{WO}_{3}$ thin films," Advanced Materials, vol. 15, no. 15, pp. 1269-1273, 2003.

[11] W. Cheng, E. Baudrin, B. Dunn, and J. I. Zink, "Synthesis and electrochromic properties of mesoporous tungsten oxide," Journal of Materials Chemistry, vol. 11, no. 1, pp. 92-97, 2001.

[12] Y. Djaoued, P. V. Ashrit, S. Badilescu, and R. Brüning, "Synthesis and characterization of macroporous tungsten oxide films for electrochromic application," Journal of Sol-Gel Science and Technology, vol. 28, no. 2, pp. 235-244, 2003.

[13] C. Santato, M. Odziemkowski, M. Ulmann, and J. Augustynski, "Crystallographically oriented mesoporous $\mathrm{WO}_{3}$ films: synthesis, characterization, and applications," Journal of the American Chemical Society, vol. 123, no. 43, pp. 10639-10649, 2001.

[14] Y. Djaoued, S. Priya, and S. Balaji, "Low temperature synthesis of nanocrystalline $\mathrm{WO}_{3}$ films by sol-gel process," Journal of Non-Crystalline Solids, vol. 354, no. 2-9, pp. 673-679, 2008.

[15] C. G. Granqvist, Handbook of Inorganic Electrochromic Materials, Elsevier, New York, NY, USA, 1995.

[16] Q. Zhong, J. R. Dahn, and K. Colbow, "Lithium intercalation into $\mathrm{WO}_{3}$ and the phase diagram of $\mathrm{Li}_{x} \mathrm{WO}_{3}$," Physical Review $B$, vol. 46, no. 4, pp. 2554-2560, 1992.

[17] A. Kuzmin, J. Purans, E. Cazzanelli, C. Vinegoni, and G. Mariotto, "X-ray diffraction, extended $\mathrm{x}$-ray absorption fine structure and Raman spectroscopy studies of $\mathrm{WO}_{3}$ powders and (1-x)WO3-y•xReO2 mixtures," Journal of Applied Physics, vol. 84, no. 10, pp. 5515-5524, 1998.

[18] O. Pyper, A. Kaschner, and C. Thomsen, "In situ Raman spectroscopy of the electrochemical reduction of $\mathrm{WO}_{3}$ thin films in various electrolytes," Solar Energy Materials and Solar Cells, vol. 71, no. 4, pp. 511-522, 2002.

[19] E. Cazzanelli, C. Vinegoni, G. Mariotto, A. Kuzmin, and J. Purans, "Low-temperature polymorphism in tungsten trioxide powders and its dependence on mechanical treatments," Journal of Solid State Chemistry, vol. 143, no. 1, pp. 24-32, 1999.

[20] T. Kudo, "A new heteropolyacid with carbon as a heteroatom in a Keggin-like structure," Nature, vol. 312, no. 5994, pp. 537538, 1984 .

[21] M. F. Daniel, B. Desbat, J. C. Lassegues, B. Gerand, and M. Figlarz, "Infrared and Raman study of $\mathrm{WO}_{3}$ tungsten trioxides and $\mathrm{WO}_{3}, \mathrm{xH}_{2} \mathrm{O}$ tungsten trioxide tydrates," Journal of Solid State Chemistry, vol. 67, no. 2, pp. 235-247, 1987.
[22] B. Pecquenard, H. Lecacheux, J. Livage, and C. Julien, "Orthorhombic $\mathrm{WO}_{3}$ formed via a Ti-stabilized $\mathrm{WO}_{3} \cdot 1 / 3 \mathrm{H}_{2} \mathrm{O}$ phase," Journal of Solid State Chemistry, vol. 135, no. 1, pp. 159-168, 1998.

[23] Powder Diffraction Files Inorganic and Organic (Card No: 85-2460 (Hexagonal-WO3), JCPDS-International Centre for Diffraction Data, PDF2 Data Base, Swarthmore, Pa, USA, 1996.

[24] M. Hibino, W. Han, and T. Kudo, "Electrochemical lithium intercalation into a hexagonal $\mathrm{WO}_{3}$ framework and its structural change," Solid State Ionics, vol. 135, no. 1-4, pp. 61-69, 2000.

[25] S. Balaji, Y. Djaoued, A. S. Albert, R. Brüning, N. Beaudoin, and J. Robichaud, "Porous orthorhombic tungsten oxide thin films: synthesis, characterization, and application in electrochromic and photochromic devices," Journal of Materials Chemistry, vol. 21, no. 11, pp. 3940-3948, 2011.

[26] C. G. Granqvist, E. Avendaño, and A. Azens, "Electrochromic coatings and devices: survey of some recent advances," Thin Solid Films, vol. 442, no. 1-2, pp. 201-211, 2003.

[27] C. Amra, "From light scattering to the microstructure of thinfilm multilayers," Applied Optics, vol. 32, no. 28, pp. 54815491, 1993. 

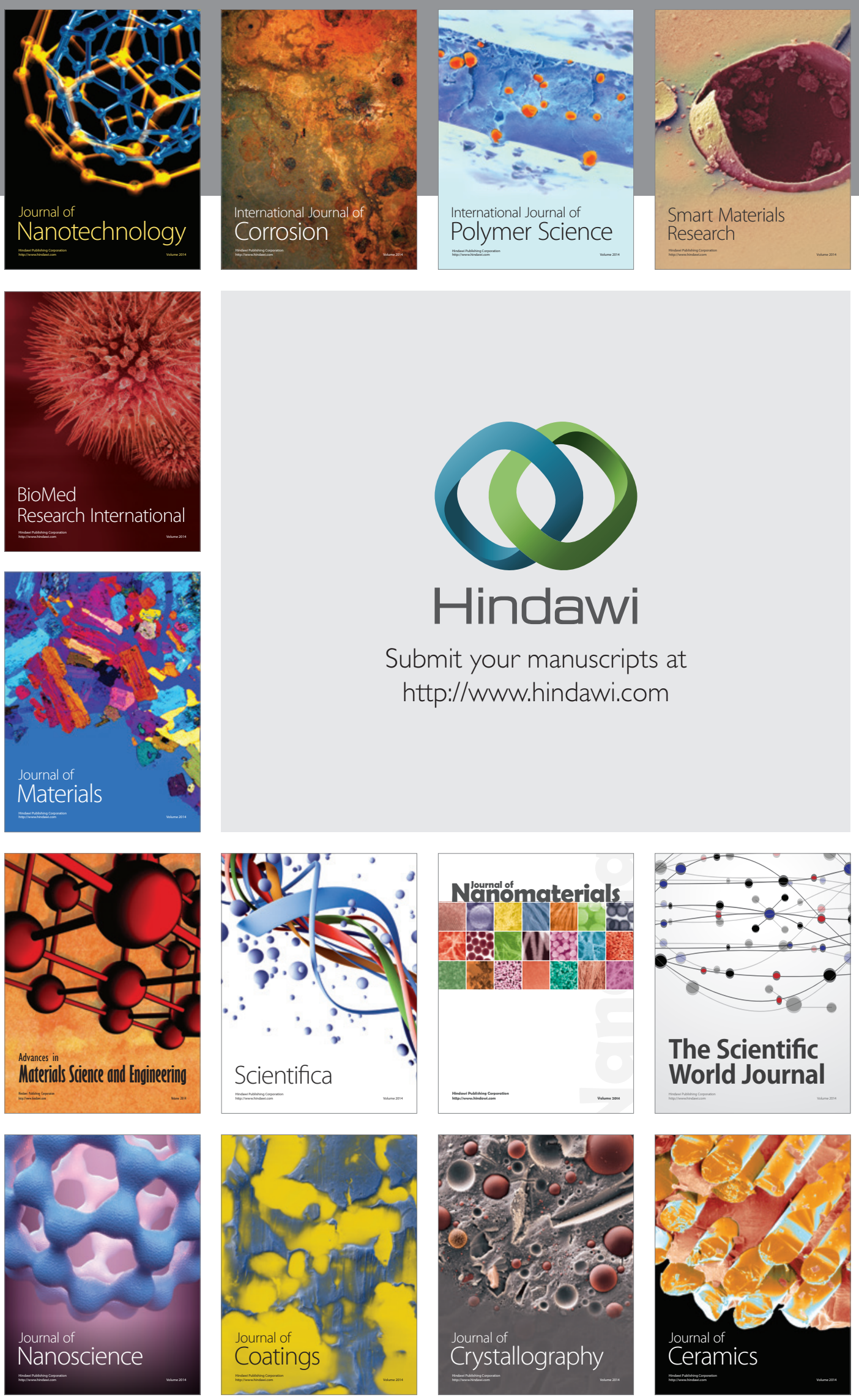

The Scientific World Journal

Submit your manuscripts at

http://www.hindawi.com

\section{World Journal}

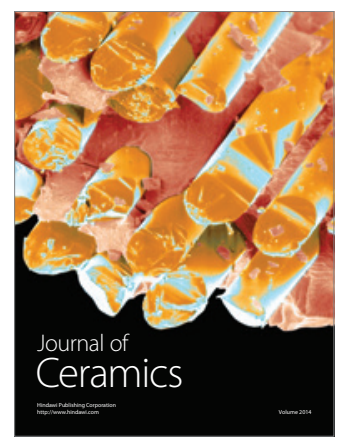

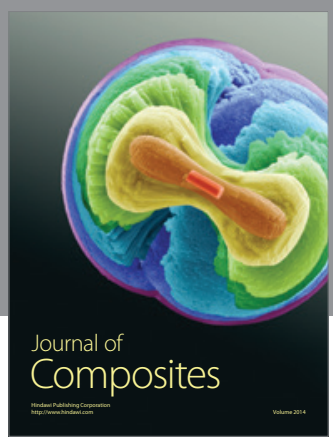
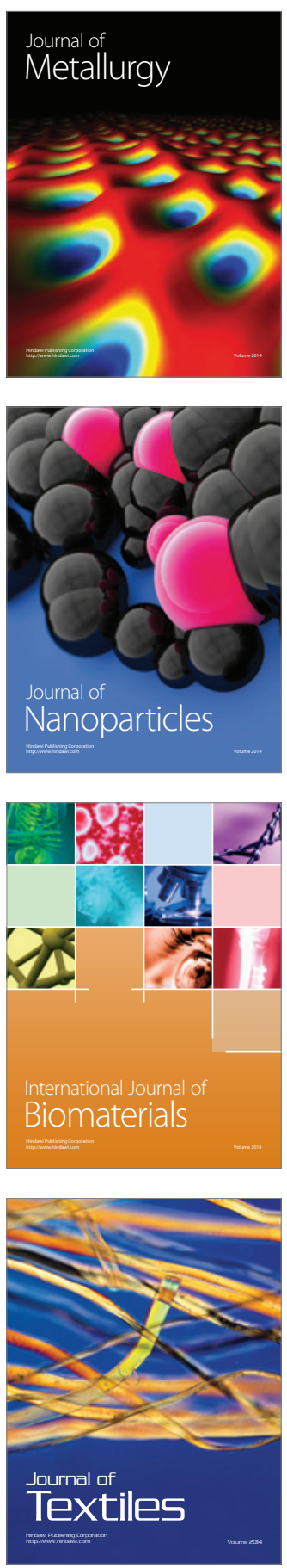